\title{
Reply to Fenici and Garofoli: Why Would Toddlers Act on Low-Level Associations Only when Processing Demands Are Reduced?
}

\author{
Peipei Setoh ${ }^{\mathrm{a}}$ Rose M. Scott ${ }^{\mathrm{b}}$ Renée Baillargeon ${ }^{\mathrm{c}}$ \\ ${ }^{a}$ Nanyang Technological University, Singapore, Singapore; ${ }^{b}$ University of California, Merced, CA, USA; \\ 'University of Illinois at Urbana-Champaign, Urbana-Champaign, IL, USA
}

\section{Keywords \\ Theory of mind · Psychological reasoning · False belief · Information processing $\cdot$ Cognitive development $\cdot$ Mental states}

In a violation-of-expectation task, Onishi and Baillargeon (2005) found that after seeing an agent hide her toy in container A as opposed to container B, 15-month-olds expected her to search A for her toy. Additional results indicated that if the agent saw the toy move to $\mathrm{B}$, infants expected her to search B; if she did not observe this displacement, they expected her to search $\mathrm{A}$, and if she saw this displacement but did not observe a second displacement in which the toy returned to A, they expected her to search B. Onishi and Baillargeon took their results as evidence of early false-belief understanding, but Perner and Ruffman (2005) proposed alternative interpretations that included an association-based account: if infants (a) could form a three-way association between the agent, the toy, and its hiding location, and (b) could readily revise this association to always reflect the last location where the agent had seen the toy, then all of the results of Onishi and Baillargeon could be explained by saying that infants responded with enhanced attention whenever an event deviated from their agent-toy-location association. This account was called into question, however, by extensive evidence from the psychological-reasoning literature showing that infants do not encode agents' actions via low-level, nonmentalistic associations, but instead reason about the motivational states (e.g., goals, preferences) and epistemic states (e.g., knowledge, ignorance) that underlie these actions (Scott, Baillargeon, Song, \& Leslie, 2010; Scott \& Baillargeon, 2014; Baillargeon, Scott, \& Bian, 2016).

In their Editor's Corner piece, Fenici and Garofoli (2020, this issue) return to an association-based account to explain the results obtained by Setoh, Scott, and Baillargeon (2016) with 2.5-year-old toddlers in a modified traditional false-belief task (for a replication, see Grosso, Schuwerk, Kaltefleiter, \& Sodian, 2019). In the task, toddlers heard a story accompanied by a picture book: Emma found an apple in one of two containers, moved it to the other container, and then went outside to play with her ball; in her absence, her brother Ethan found the apple and took it away. Emma then returned to look for her apple. In the test trial, children were shown pictures of the two containers and were asked the test question, "Where karger@karger.com

(c) 2020 S. Karger AG, Basel

Karger"
Peipei Setoh

Psychology, School of Social Sciences

Nanyang Technological University

48 Nanyang Avenue, Singapore 639818 (Singapore)

psetoh@ntu.edu.sg 
will Emma look for her apple?" The task included two modifications designed to reduce processing demands. One modification was that Emma's brother took the apple away to an undisclosed location. This modification built on findings that children aged 3.5 years and older typically perform better at traditional tasks if the test object is absent from the scene (Wellman, Cross, \& Watson, 2001), presumably because children then require less inhibitory control to suppress their knowledge of the object's current location when asked the test question. The other modification was that during the story, toddlers were asked two practice questions designed to reduce the response generation demands of the test question. In one question, toddlers saw an apple and a banana and were asked, "Where is Emma's apple?"; in the other question, they saw a ball and a frisbee and were asked, "Where is Emma's ball?" These questions gave children practice interpreting a "where" question and producing a response by pointing to one of two pictures. With these two modifications, toddlers performed above chance in the test trial, pointing to the container that Emma falsely believed held her apple. Additional results indicated that toddlers performed at chance if they received either zero or one practice question, suggesting that at least two practice questions were needed to effectively reduce response generation demands. Recent results (Antilici \& Baillargeon, 2020) suggest that toddlers succeed with two practice "where" questions even when these occur at the start of the testing session and involve objects unrelated to the false-belief story.

To explain the positive results that Setoh et al. (2016) obtained with two practice questions, Fenici and Garofoli (2020, this issue) argue that toddlers (1) formed a three-way association between Emma, her apple, and the container where she hid it, and (2) answered the test question based on this association. To explain the negative results that Setoh et al. obtained with zero or one practice questions, Fenici and Garofoli argue that toddlers needed response generation practice to be able to answer the test question based on the three-way association they had formed. Without such practice, they suggest, the processing demands associated with the test question tended to "disrupt children's newly created associations between Emma, the apple, and the more salient container, thereby making it unsurprising that children answered at chance." In other words, toddlers could act on their three-way association "only when the computational demands of the test question were sufficiently relieved by proper intervention."
We have three difficulties with the association-based interpretation proposed by Fenici and Garofoli (2020, this issue). First, it seems implausible that toddlers could easily form and revise a low-level agent-toy-location association but also have difficulty using this association to respond to the test question when they receive zero or one practice trials. The whole point of association-based explanations is that what appears to be evidence of sophisticated psychological reasoning can instead be explained by a shallow, automatic, nonmentalistic response. From this viewpoint, the cognitive demands of the test question would be expected to have little effect on toddlers, who should be just as likely to point to the container associated with Emma whether they receive zero, one, or two practice trials. There should be no need for a "proper intervention" to reduce processing demands in order to help toddlers make use of their association.

Second, even if an association-based explanation was broadened to take into account the cognitive demands of the test question, past research has shown that adults and children are typically more likely to fall back on low-level heuristics when cognitive demands increase and prevent more sophisticated strategies (Epley \& Gilovich, 2006; Cimpian \& Salomon, 2014; Borst, Aïte, \& Houdé, 2015). By this logic, one would predict that toddlers would be more likely to fall back on a low-level heuristic and point to the container associated with Emma when they receive zero or one versus two practice trials, due to the increased cognitive demands of the test question. This is the opposite prediction from that offered by Fenici and Garofoli (2020, this issue).

Third, as converging evidence of early false-belief understanding continues to accumulate (for reviews, see Scott \& Baillargeon, 2017; Scott, Roby, \& Baillargeon, in press), some of these new results appear particularly difficult to explain via agent-toy-location associations. For example, in a near-infrared spectroscopy experiment, 7-month-olds, like adults, showed greater activation in the temporal-parietal junction when an agent did not see her toy transferred from container A to container B (falsebelief scenario) than when she either observed this transfer (true-belief scenario) or could infer it because the containers were transparent (direct-perception scenario; Hyde, Simon, Ting, \& Nikolaeva, 2018). As another example, in a social-preference experiment, 2-year-olds preferred a character who helped a protagonist look for a toy over a character who hindered the protagonist, even though the helper failed to help because she held a falsebelief about the toy's location (Yuile, Baillargeon, \& Fish- 
er, 2020). Neither of these results is easily explained by an assumption that toddlers are limited to forming and revising agent-toy-location associations.

In a recent commentary, Carruthers (2018) argued that there are now too many false-belief studies with infants and toddlers, using too many variations in materials and methods, for association-based and other low-level accounts to be plausible. The arguments offered by Fenici and Garofoli (2020, this issue) do not convince us otherwise.

\section{Acknowledgments}

We thank Francesco Antilici, Dan Hyde, and Amanda Rose Yuile for helpful comments and suggestions.

\section{Funding Sources}

Rose Scott was funded by NSF (\#1844416), and Peipei Setoh was funded by a Singapore Ministry of Education Social Science Research Thematic Grant (MOE2016-SSRTG-017) at the time of the development of this work.

\section{References}

Antilici, F., \& Baillargeon, R. (2020, July). 2.5 -year-olds pass an explicit unexpectedtransfer false-belief task when processing demands are reduced. Poster to be presented at the Biennial Meeting of the International Congress of Infant Studies, Glasgow, UK.

Baillargeon, R., Scott, R. M., \& Bian, L. (2016). Psychological reasoning in infancy. Annual Review of Psychology, 67(1), 159-186. https:// doi.org/10.1146/annurev-psych-010213115033

Borst, G., Aïte, A., \& Houdé, O. (2015). Inhibition of misleading heuristics as a core mechanism for typical cognitive development: Evidence from behavioural and brain-imaging studies. Developmental Medicine and Child Neurology, 57(Suppl 2), 21-25. https://doi.org/ 10.1111/dmcn.12688

Carruthers, P. (2018). Young children flexibly attribute mental states to others. Proceedings of the National Academy of Sciences of the United States of America, 115(45), 11351-11353. https://doi.org/10.1073/pnas.1816255115

Cimpian, A., \& Salomon, E. (2014). Author's reply: Refining and expanding the proposal of an inherence heuristic in human understanding. Behavioral and Brain Sciences, 37(5), 506-527. https://doi.org/10.1017/ S0140525X14000028

Epley, N., \& Gilovich, T. (2006). The anchoringand-adjustment heuristic: Why the adjustments are insufficient. Psychological Science, 17(4), 311-318. https://doi.org/10.1111/j.14679280.2006.01704.x
Fenici, M., \& Garofoli, D. (2020). An associationist bias explains different processing demands for toddlers in different traditional false-belief tasks. Human Development, this issue. https:// doi.org/10.1159/000505208

Grosso, S. S., Schuwerk, T., Kaltefleiter, L. J., \& Sodian, B. (2019). 33-month-old children succeed in a false belief task with reduced processing demands: A replication of Setoh et al. (2016). Infant Behavior and Development, 54,151-155. https://doi.org/10.1016/j.infbeh. 2018.09.012

Hyde, D. C., Simon, C. E., Ting, F., \& Nikolaeva, J. I. (2018). Functional organization of the temporal-parietal junction for theory of mind in preverbal infants: A near-infrared spectroscopy study. The Journal of Neuroscience, 38(18), 4264-4274. https://doi.org/10.1523/ JNEUROSCI.0264-17.2018

Onishi, K. H., \& Baillargeon, R. (2005). Do 15-month-old infants understand false beliefs? Science, 308(5719), 255-258. https://doi. org/10.1126/science.1107621

Perner, J., \& Ruffman, T. (2005). Psychology. Infants' insight into the mind: How deep? Science, 308(5719), 214-216. https://doi.org/ $10.1126 /$ science. 1111656

Scott, R. M., \& Baillargeon, R. (2014). How fresh a look? A reply to Heyes. Developmental Science, 17(5), 660-664. https://doi.org/10.1111/ desc. 12173
Scott, R. M., \& Baillargeon, R. (2017). Early falsebelief understanding. Trends in Cognitive Sciences, 21(4), 237-249. https://doi.org/ 10.1016/j.tics.2017.01.012

Scott, R. M., Baillargeon, R., Song, H. J., \& Leslie, A. M. (2010). Attributing false beliefs about non-obvious properties at 18 months. Cognitive Psychology, 61(4), 366-395. https://doi. org/10.1016/j.cogpsych.2010.09.001

Scott, R. M., Roby, E., \& Baillargeon, R. (in press). How sophisticated is infants' theory of mind? In O. Houdé \& G. Borst (Eds.), Cambridge handbook of cognitive development. Cambridge, UK: Cambridge University Press.

Setoh, P., Scott, R. M., \& Baillargeon, R. (2016). Two-and-a-half-year-olds succeed at a traditional false-belief task with reduced processing demands. Proceedings of the National Academy of Sciences of the United States of America, 113(47), 13360-13365. https://doi. org/10.1073/pnas.1609203113

Wellman, H. M., Cross, D., \& Watson, J. (2001). Meta-analysis of theory-of-mind development: The truth about false belief. Child Development, 72(3), 655-684. https://doi. org/10.1111/1467-8624.00304

Yuile, A. R., Baillargeon, R., \& Fisher, C. (2020, July). Two-year-olds demonstrate false-belief understanding in a novel intent-based socialpreference task. Poster to be presented at the Biennial Meeting of the International Congress of Infant Studies, Glasgow, UK. 